\title{
Construindo um objeto de pesquisa em Arquivologia: algumas reflexões
}

\author{
Georgete Medleg Rodrigues \\ georgete@unb.br \\ Doutora em História \\ Professora do Curso de Arquivologia e do Programa de Pós-Graduação em Ciência da \\ Informação da Universidade de Brasília
}

\begin{abstract}
Resumo: Todo docente que integra um programa de pós-graduação precisa ter um projeto de pesquisa. $\mathrm{O}$ tema a ser investigado pode vir com o pesquisador, a partir de suas experiências acadêmicas ou profissionais anteriores ao seu ingresso na universidade, ou pode ser construído nessa nova etapa, seja porque surgem novas inquietações ou porque ele/ela constata que existem problemas de sua área de conhecimento ainda não estudados, ou insuficientemente pesquisados. Um tema de pesquisa desdobra-se, cresce, suscita novas questões, novos problemas. Espraia-se entre outros pesquisadores. Neste artigo a autora narra o seu percurso na construção de um objeto de pesquisa arquivístico e que viria a ser um projeto de investigação no Programa de pós-graduação em Ciência da Informação da UnB sobre a pesquisa em Arquivística na pós-graduação no Brasil. A pesquisa resultou inicialmente em um artigo de mesmo título publicado no primeiro número de Cenário Arquivístico, revista da Abarq, em 2002. O trabalho abriu novas sendas de pesquisa, iniciando com um projeto de iniciação científica, este último sendo, finalmente, revisitado e ampliado em um mestrado e doutorado. Conclui ressaltando que o tema demonstra seu vigor, interesse a atualidade em trabalhos de outros pesquisadores, justificando sua importância e necessidade para o enriquecimento da área.
\end{abstract}

Palavras-chave: arquivologia; pesquisa; pós-graduação; graduação; metodologia.

\section{An object in Archival research: some reflections}

\begin{abstract}
Every teacher that integrates a program graduate must have a research project. The topic to be investigated with the researcher can come from academic or professional experiences prior to their entry into university, or can be built in this new stage, new concerns arise either because or because he / she finds that there are problems in their knowledge areas not yet studied, or insufficiently researched. A research theme unfolds, grows, raises new questions, new problems. Spreads among other researchers. In this article we narrate our journey in building an object of archival research that would be a research project on Archival science research in graduate school in Brazil, which resulted in an article of the same title published in the first issue of Cenário Arquivístico in 2002 and an undergraduate research project, the latter being finally revisited, expanded and enriched by other researchers, explaining your interest and the need for the enrichment of the area.
\end{abstract}

Key words: archival science; research; postgraduate; undergraduate; methodology. 


\section{Introdução}

Para saber construir o objeto e conhecer o objeto que é construído é necessário ter consciência de que todo objeto propriamente científico é consciente e metodicamente construído, e é necessário conhecer tudo isso para nos interrogarmos sobre as técnicas de construção das perguntas formuladas ao objeto.

(Pierre Bourdieu, Jean-Claude Chamboredon, Jean-Claude Passeron, A profissão de sociólogo, 2002).

Toda obra é responsável. Publicar é se engajar, tomar responsabilidades diante da sociedade, diante do leitor, diante das consequências que um argumento poderia ter.

(George Steiner, George Steiner à luz de si mesmo, 2003)

maneira do historiador Georges
Duby (1993) aventuro-me a
dizer que a história que pretendo compartilhar com os leitores deste número de Informação $A r$ quivística começa em 2001. Como se trata de narrar um percurso individual ${ }^{1}$, permito-me, nessa narrativa, usar a primeira pessoa do singular. Naquele ano, instigada por Vanderlei Batista dos Santos, então integrante da diretoria da Associação Brasiliense de Arquivologia - Abarq e meu orientando de mestrado no Programa de Pós-Graduação em Ciência da Informação da Universidade de Brasília, comecei a esboçar o que seria um projeto de pesquisa para vários anos: a pesquisa em Arquivologia no Brasil. Observo que, na ocasião, nem eu

\footnotetext{
${ }^{1}$ No sentido da singularidade da trajetória e não naquele de autossuficiência.
}

mesma sabia que esse seria o título de um projeto de pesquisa. Eu estava há apenas um ano na pós-graduação em Ciência da Informação do então Departamento de Ciência da Informação e Documentação da Universidade de Brasília - $\mathrm{CID}^{2}$ e há dois no curso de Arquivologia da mesma universidade, onde entrei ainda com diploma de mestre, o doutorado tendo sido obtido no mesmo ano, porém alguns meses depois do concurso para professor, ou seja, em 1998.

Qual era, então, a minha relação com a Arquivologia? Eu diria que, com a disciplina, à época, quase nenhuma. Em contrapartida, sempre fui apaixonada pelos arquivos, desde a graduação em história na Pontifícia Universidade Católica de São Paulo - PUC/SP, no final dos anos 1970, início dos 80. Desde que a oportunidade surgiu, interessei-me pelo tema dos arquivos e o que eles poderiam “dizer" sobre o período da Ditadura militar. A experiência de recolhimento, por alguns arquivos estaduais, dos

\footnotetext{
2 Atualmente, Faculdade de Ciência da Informação - FCI, abrigando três cursos de graduação - Arquivologia, Biblioteconomia e Museologia - e uma pós-graduação com mestrado e doutorado em Ciência da Informação.
} 
arquivos dos DOPS/DOI-CODI ${ }^{3}$ a partir de meados dos anos 1980, com ampla divulgação pela imprensa, fez-me pensar que os "arquivos da repressão" poderiam ser o tema principal do primeiro número da revista Quadrilátero, do Arquivo Público do Distrito Federal - $\mathrm{ArPDF}^{4}$. Trabalhando em um arquivo público eu podia, enfim, unir dois interesses: a paixão pela história e pelos arquivos, convergindo, ambos, para a ideia subjacente de que os arquivos precisam de cuidados específicos para ser acessíveis e, sendo assim, responderem às perguntas feitas pelos pesquisadores. Sim, aqui, defendo a tese de que os arquivos não são, por si mesmos, portadores de respostas para a história, mas respondem às indagações que lhes são feitas. Entretanto, como vou expor mais adiante, esse tema, ainda que caro para mim, precisaria esperar algum tempo antes de se tornar outro objeto de pesquisa. Quando cheguei à universidade como professora do curso de Arquivologia, as demandas eram outras. Como boa "kantiana", deixei de lado

$\begin{array}{llcr}3 & \text { Delegacia de } & \text { Ordem } & \text { Política } \\ \text { Social/Destacamento } & \text { de } & \text { Operações }\end{array}$
Internas/Centro de Operações de Defesa Interna.

4 QUADRILÁTERO. Revista do Arquivo Público do Distrito Federal. Brasília, v. 1, n. 1, março/agosto 1998. meus projetos, para abraçar o que era mais coletivo e premente. Eu não sabia, mas, na prática, eu estava na posição apontada por Anne Pederson (1994), segundo a qual

o pequeno número de pesquisadores em arquivística explica, em larga medida, a relativa lentidão de seu desenvolvimento e, por causa disso, o desenvolvimento da disciplina. (PERDESON, 1994 apud COUTURE, 20012002, p. 42-43, tradução nossa)

Após esse preâmbulo, passo, em seguida, a narrar a construção do que julgo ter sido o meu primeiro objeto de pesquisa em Arquivologia, pensado no interior mesmo da disciplina e por que ele se impôs, para mim, à frente de outros.

\section{Aproximações...}

Todo docente que integra um programa de pós-graduação precisa ter um projeto de pesquisa. Isso é praxe em qualquer país. O tema a ser investigado pode vir com o pesquisador, a partir de suas experiências acadêmicas ou profissionais anteriores ao seu ingresso na universidade, ou pode ser construído nessa nova etapa, seja porque surgem novas inquietações ou porque ele/ela constata que existem problemas de sua área de conhecimento ainda não estudados, ou insuficientemente pes- 
quisados. Algo similar a um projeto de pesquisa para mestrado, com mais força no doutorado. No caso do professor, muitas vezes, a sala de aula, as inquietações dos alunos, as perguntas que lhe são feitas são o ponto de partida para a elaboração de um problema de pesquisa. No meu primeiro semestre na UnB como professora também da pósgraduação, eu acumulava três disciplinas na graduação com uma na pós, além de dois orientandos de mestrado que haviam sido selecionados em processo seletivo anterior ao meu ingresso na pós. ${ }^{5}$ De todo modo, quando ingressei na UnB, eu já vinha de uma experiência em instituição arquivística, no caso o ArPDF, inicialmente na gerência de conservação e, depois, na de arquivo permanente. E com uma passagem pelo Arquivo Nacional, no estágio técnico oferecido pela instituição, ocasião rara de ter Michel Duchein como professor ${ }^{6}$.

\footnotetext{
5 Agradeço enormemente aos meus dois mestrandos da época - Alexandra e Vanderlei pela confiança no percurso que iniciamos meio às escuras, mas que nos permitiu crescer e amadurecer certas questões da disciplina, dentre elas o problema do acesso aos arquivos e dos documentos eletrônicos. A primeira - o acesso viria a se constituir no meu tema principal de pesquisa atualmente.

${ }^{6}$ Participei do estágio na condição de servidora do ArPDF e nessa função começava a entender, na prática, a terminologia arquivística, como os conceitos de fundo e série; de arquivo corrente, intermediário e permanente. As aulas com
}

De usuária dos arquivos, passei para o de mediadora. Pela primeira vez eu tinha consciência da responsabilidade e do savoir faire específicos dos arquivistas. Diante da enormidade das tarefas (o termo aqui não é pejorativo, muito pelo contrário) exigidas do arquivista, ousei mesmo julgar o ofício de historiador, entre os quais me incluía, como uma espécie de "predador" dos arquivos, concepção imediatamente revista após reler a argumentação de Michel de Certeau (1982) referindo-se à "desconstrução" dos arquivos como atividade própria do historiador. Não que essa "desconstrução" dos arquivos não seja feita também pelos arquivistas: o que é um catálogo, senão, primeiramente, um instrumento de pesquisa ${ }^{7}$ que "desconstrói" a lógica dos fundos de arquivo, aos quais o arquivista imprime uma nova (temática, tipológica, etc)?

\section{A "escolha" do tema, construção do objeto}

Michel Duchein vieram esclarecer, teoricamente, esses conceitos.

7 Um instrumento de pesquisa é sempre uma representação da "coisa", no caso um fundo, uma série, subsérie, grupos, etc, e não a "coisa em si". Insisto sempre com os meus alunos na natureza puramente intelectual e abstrata dos instrumentos de pesquisa. 
Retomando a construção do meu objeto de pesquisa, vem-me à mente a pergunta de Vanderlei nesse (já distante) 2001: "Por que você não escreve algo sobre a pesquisa em Arquivologia no Programa de Pós-Graduação em Ciência da Informação da UnB para apresentar no evento comemorativo do dia do arquivista e dos dez anos do curso de Arquivologia da Universidade de Brasília?”. Pensei comigo: escrever o quê? Existe pesquisa em Arquivologia na UnB? Eu sabia apenas dos meus dois orientandos que trabalhavam com temáticas arquivísticas. Confesso agora que eu era uma orientadora hesitante, ainda desbravando essa terra incógnita que era, para mim, a Arquivologia. Veiome imediatamente à mente um livro recém-adquirido, que eu havia lido muito rapidamente ainda na livraria intitulado A arte da pesquisa (BOOTH; COLOMB; WILLIAMS, 2000). Voltei ao livro, como uma iniciante, retomando o capítulo sobre "fazer perguntas" científicas. Nesse capítulo, os autores afirmam que

quase todos nós começamos um projeto de pesquisa sem estarmos diretamente certos de qual é o problema e às vezes nosso mais importante resultado é simplesmente esclarecer esse ponto (BOOTH; COLOMB; WILLIAMS, 2000, p.78).
Isso fazia todo o sentido na situação na qual me encontrava.

Mais confiante, aceitei o desafio e, desde aquele momento, fiquei pensando em como realizar tal projeto. De imediato, concluí que tal pesquisa deveria extrapolar o PPGCInf. Como prezo muito o trabalho em parceria, convidei a minha orientanda de mestrado, a angolana Maria Alexandra Miranda Aparício, bolsista PEC-PG ${ }^{8}$, que, nessa condição, podia consagrar um tempo maior a uma pesquisa paralela à sua dissertação de mestrado. Aqui, abro parênteses novamente para evocar os três autores citados acima, quando eles nos lembram do quanto o trabalho de pesquisa, longe do estereótipo de isolamento, está sempre dialogando com outros pesquisadores por meio dos livros, artigos, congressos, etc, e da necessidade imperiosa desse diálogo (BOOTH; COLOMB; WILLIAMS, 2000). Esse diálogo, acrescento, estende-

\footnotetext{
8 Programa de Estudante Convênio de PósGraduação, um programa CAPES, CNPq e Ministério das Relações Exteriores que tem como objetivo "a formação de recursos humanos, com vistas a que cidadãos oriundos de países em desenvolvimento, com os quais o Brasil mantém Acordo de Cooperação Educacional, Cultural ou de Ciência e Tecnologia, possam vir a realizar estudos de pós-graduação em Instituições de Ensino Superior brasileiras". (Cf. http://www.capes.gov.br/images/stories/downloa d/editais/Edital_042_PEC_PG_2012.pdf).
} 
se às parcerias entre orientador e orientando e à cumplicidade, em vários níveis, que se instaura desde então entre ambos.

\section{O artigo de Cenário Arquivístico: delineamento de um projeto de pesquisa}

Convite aceito (pela Alexandra e por mim) restava, agora, planejar a pesquisa. Comecei estabelecendo um cronograma de leitura sobre a disciplina Arquivologia. A leitura mais importante naquele momento foi a do livro do trio canadense Couture, Martineau e Ducharme (1999) ${ }^{9}$, traduzido por Luís Carlos Lopes, em que são assentadas as bases para uma reflexão sobre o tema da pesquisa e da formação em Arquivologia, bem como oferece um amplo espectro de temas de pesquisa na área $^{10}$. Em seguida, buscamos identificar

\footnotetext{
${ }^{9}$ Os resultados mais consistentes do programa de pesquisa dos canadenses foi publicado na revista Archives, v. 33, n. 2, 2001-2002. Disponível em http://www.archivistes.qc.ca/revuearchives/vol33 _2/33-2-couture.pdf. Não conhecíamos ainda a tese de Maria Odila Kahl Fonseca que somente seria defendida em 2004 cujo foco central é a Arquivologia e sua relação com a Ciência da Informação (FONSECA, 2004).
}

10 Gostaria de registrar aqui o meu agradecimento póstumo a Luís Carlos Lopes por esse importantíssimo trabalho de divulgação da obra de Carol Couture e colaboradores. Como estamos falando de construção de um objeto de pesquisa, um deles, sem dúvida, seria sobre o papel da tradução e dos tradutores de obras de na bibliografia brasileira a existência de trabalhos sobre a pesquisa em Arquivologia no Brasil e quais seriam as abordagens. O livro mais importante tangenciando o tema, mas cujo enfoque era, sobretudo, a formação inicial em Arquivologia, ou seja, a graduação é aquele organizado por Jardim e Fonseca (1999), embora os dois autores, especialmente Jardim, tratasse da produção do conhecimento em Arquivologia. ${ }^{11}$ Essas leituras iniciais levaram-me à conclusão de que o tema da pesquisa poderia ser "A pesquisa em Arquivística na pós-graduação no Brasil", o mesmo título do artigo que publiquei, em coautoria com Alexandra Aparício, no primeiro número de Cenário Arquivístico, revista da Abarq, em $2002^{12}$. Outro documento importante para nos ajudar a compreender a inserção disciplinar da Arquivologia,

Arquivologia para o desenvolvimento da disciplina no Brasil. A identificação e a compreensão do porquê de se traduzir esta ou aquela obra e quais as línguas preferenciais nos dirão bastante sobre o percurso da disciplina e a recepção dos conceitos e métodos.

11 Particularmente os capítulos de autoria de Maria Tereza Navarro de Britto e de José Maria Jardim e Maria Odila Fonseca, ambos abordando o ensino universitário.

12 O título completo é: "A pesquisa em Arquivística na pós-graduação no Brasil: balanço e perspectivas". 
bem como as condições desta inserção, do ponto de vista das agências nacionais de pesquisa, foi a publicação do Conselho Nacional de Desenvolvimento Científico e Tecnológico - CNPq, intitulada Avaliação e Perspectivas, no volume dedicado às Ciências Sociais Aplicadas (CNPq, 1983), onde são abordadas questões relacionadas à Arquivologia, especialmente sobre a necessidade de se formar pesquisadores na área. Após essas leituras, observei para Alexandra que algumas premissas poderiam nortear a nossa pesquisa, como queria Couture et al. (1999), quais sejam:

1. A pesquisa precisa de um ambiente que a anime e que favoreça o seu desenvolvimento.

2. $\mathrm{O}$ percurso da Arquivologia mostra que a pesquisa nesse campo estabeleceu e deve estabelecer relações inter e multidisciplinares ${ }^{13}$.

3. A Arquivologia possui um objeto de estudo distinto de outras disciplinas.

4. Assim como ocorreu - e ainda ocorre - com outras disciplinas, a

13 Esse aspecto foi muito pouco abordado no artigo em questão, mas brilhantemente retomado pela minha atual colega Angelica Alves da Cunha Marques (2010) em sua tese de doutorado sob minha orientação. Na verdade, Angelica, mais que eu, investiu esforços intelectuais e reflexões desafiadoras sobre a questão da inter, trans e multidisciplinaridade da Arquivologia. pesquisa é essencial para o desenvolvimento da Arquivologia como disciplina do conhecimento.

5. Embora as práticas arquivísticas sejam bastante antigas, a Arquivologia, como disciplina, é um fenômeno contemporâneo e é como tal que devemos compreendê-la.

Assim, a minha narrativa agora vai sintetizar o que publicamos no primeiro número de Cenário Arquivístico, como indicado anteriormente. Embora, não tenha sido explicitado no referido artigo (questão de espaço), o problema da pesquisa foi estruturado, então, da seguinte forma:

\section{$\underline{\mathrm{PC}=\text { Problema Central ou questão }}$ norteadora da pesquisa.}

Podemos falar de pesquisa em Arquivologia nas universidades no Brasil? Se sim, como essa pesquisa se configura e em qual espaço institucional?

Como estávamos falando de pesquisa na universidade, o lócus privilegiado para o seu desenvolvimento era a pós-graduação. Evidentemente, nesse caso, era preciso um recorte: todos os programas de pós-graduação seriam 
inviáveis. Optou-se, então, por aqueles com mais afinidade com a área, como indicado no artigo de Cenário Arquivístico:

[...] um diagnóstico sobre as pesquisas em Arquivística e suas perspectivas futuras, no Brasil, deve, inicialmente, mapear os programas de pós-graduação que têm linhas de pesquisa ou desenvolvam pesquisas sobre temáticas da área. (RODRIGUES; APARICIO, 2002, p. 31)

\section{Como tínhamos prazo para} apresentar os resultados da pesquisa e que este precisaria conter dados empíricos, palpáveis, sobre a pesquisa em Arquivologia no Brasil, não poderíamos nos alongar sobre os fundamentos teóricos da pesquisa. Contudo, à medida que avançávamos na coleta de dados e nas leituras, ficava claro que estávamos apenas começando. No mesmo artigo, ao nos referirmos aos dados que mostrariam um retrato mais próximo da realidade da disciplina, escrevemos que

outros indicadores também devem ser incluídos para que se tenha um quadro mais preciso: publicações especializadas, produção quantitativa e qualitativa, temáticas, investimento financeiro, etc. (RODRIGUES; APARICIO, 2002, p. 31).

O plano de trabalho inicial da pesquisa, com suas respectivas etapas, ficou estabelecido da seguinte forma: levantamento dos cursos de graduação em Arquivologia no Brasil; levantamento dos Programas de PósGraduação no Brasil mais identificados com a Arquivologia (Ciência da Informação, Comunicação, Biblioteconomia, História), identificando a universidade, $\mathrm{o}$ departamento, as áreas de concentração e suas respectivas linhas de pesquisa; identificação das dissertações e teses de doutorado defendidas nesses programas, cuja temática aproxima-se, pelo objeto e pela abordagem, da Arquivologia, com os respectivos orientadores, autores e departamentos; definição de conjuntos temáticos nos quais essas pesquisas poderiam ser agrupadas; identificação do financiamento para projetos de pesquisa na área; identificação, na literatura nacional da área, do que é resultado de pesquisas desenvolvidas em programas de pós; quantificar e qualificar os alunos egressos dos cursos de Arquivologia nos programas de pós-graduação; participação de professores e alunos dos cursos de Arquivologia no Programa Institucional de Bolsas de Iniciação Científica - PIBIC; identificação do perfil dos orientadores (RODRIGUES; APARICIO, 2002, p. 32). No mesmo artigo, compartilhávamos com nossos 
leitores as fontes de informação utilizadas:

Os dados aqui apresentados foram levantados em setembro e outubro de 2001 no catálogo de teses e dissertações do IBICT em Brasília; no acervo de teses e dissertações do Programa de Pós-Graduação em Ciência da Informação da Universidade de Brasília e nos Anais do PIBIC da UnB, além de páginas da Internet (RODRIGUES; APARICIO, 2002, p. 31).

No referido artigo foram publicados cinco quadros, todos buscando sintetizar os dados relacionados a cinco das nove etapas do Plano de Trabalho: os nomes dos cursos de pósgraduação em Ciência da Informação no Brasil, o nível do curso (mestrado, doutorado), ano de início e suas respectivas linhas de pesquisa (Quadro $1)^{14}$; todos os cursos de graduação em Arquivologia nas universidades brasileiras, o nome dos departamentos aos quais estavam vinculados e o estado da federação (Quadro 2); as dissertações e teses defendidas nas universidades com temáticas arquivísticas naqueles pro-

${ }^{14}$ Curiosamente, ao contrário do proposto, não indicamos as áreas de concentração, embora estas tivessem sido identificadas no levantamento de dados. Um lapso lamentável mas que, infelizmente, acontece. Daí a necessidade de muita revisão dos textos antes de serem enviados para publicação, o "polimento final", ao qual se referem Booth; Colomb; Williams (2000). gramas previamente definidos (Comunicação, Biblioteconomia, História, Ciência da Informação), quadro com duas colunas para o nome do Programa e outra para os autores, título, ano de defesa e orientador (Quadro 3); um quadro agrupando as teses e dissertações segundo grandes grupos temáticos de pesquisa e os respectivos programas onde os trabalhos foram realizados (Quadro 4); finalmente, um quadro com as pesquisas realizadas no âmbito da iniciação científica - IC (PIBIC), mas apenas na Universidade de Brasília (Quadro 5) (RODRIGUES; APARICIO, 2002, p. 33-37).

Com base na análise dos dados sintetizados nos quadros referenciados acima, as duas autoras (RODRIGUES; APARICIO, 2002, p. 38), concluíram que:

- $\quad$ O objeto de estudo da Arquivologia encontrava-se disperso em várias áreas do conhecimento;

- $\quad$ A dispersão pode levar à afirmação do caráter inter e multidisciplinar da Arquivologia?

- A quantidade (pouca) de teses e dissertações com temas arquivísticos demonstra a baixa produção de pesquisa científica na área. 
- $\quad$ USP, IBICT/UFRJ e a UnB são as universidades com mais dissertações e teses com temáticas arquivísticas.

- Ainda são poucas as linhas de pesquisa na pós-graduação direcionadas para a Arquivologia.

- Os cursos de graduação em Arquivologia estão implantados em faculdades e departamentos diferenciados, tanto em Ciências Humanas quanto em Ciências Sociais.

- Tal constatação parece refletir a ausência de um consenso quanto ao enquadramento institucional/conceitual da Arquivologia no Brasil.

- $\quad$ As áreas temáticas de pesquisa são amplas e sua concentração pode ter relação com a produção dominante nos cursos de pós-graduação.

- $\quad$ Alguns temas são predominantes na escolha dos autores das pesquisas.

- A produção científica na graduação, via iniciação científica, ainda é rara, no caso da UnB, única instituição pesquisada, fato que pode ser explicado pelo fato de o curso ser noturno.

- Os docentes do curso de Arquivologia da UnB desenvolvem pesquisas em sintonia com as questões atuais da área, bem como se constatou que pesquisas desenvolvidas como dissertação de mestrado, tornam-se projetos de pesquisa em IC.

\section{Em torno de um objeto comum: a parceria orientando-orientador}

Em 2002, a trilha aberta em 2001 começa a alargar-se, tomar ares de estrada. Naquele ano, tive a oportunidade de conhecer Angelica Alves da Cunha (ainda não era Marques...) cujo entusiasmo em participar de um projeto de IC contrastava com a relativa indiferença dos seus colegas. ${ }^{15}$ Como se sabe, o plano de trabalho dos orientandos de IC deve estar vinculado a um projeto de pesquisa do professor, algo já destacado por Umberto Eco:

Por vezes o estudante escolhe um tema de seu próprio interesse. Outras vezes, ao contrário, aceita a sugestão do professor a quem pede a tese. Ao sugerirem temas, os professores podem seguir dois critérios: indicar um assunto que conheçam bem e onde não terão dificuldades em acompanhar o aluno, ou recomendar um tema que conheçam pouco e querem conhecer mais (ECO, 1988, p. 33).

Vendo retrospectivamente, creio que, dado o estágio da pesquisa naquele momento, eu preenchia o segundo critério. Novamente recorro a Eco (1988) para uma justificativa dessa postura:

15 Quase "perdi" Angelica naquela ocasião, pois, devido a duas grandes perdas afetivas entre 2001 e 2002 eu andava meio down, sem vontade de muito esforço intelectual. Aliado ao fato de eu não a conhecer, dado que ela não havia sido minha aluna na graduação. 
Fique claro que contrariamente à primeira impressão, esse segundo critério [recomendar um tema que o orientador conhece pouco] é o mais honesto e generoso. $\mathrm{O}$ professor raciocina que, acompanhando uma tese dessas, terá seus próprios horizontes alargados [...] (ECO, 1988, p. 33).

Propus então para Angelica prosseguir com o tema já descrito anteriormente, apenas levemente desbravado. O seu plano de trabalho intitulava-se então "A pesquisa em Arquivística no Brasil: um estudo da produção científica nos programas de pós-graduação e de iniciação científica e do papel das agências financiadoras". 16 Como podemos constatar o tema inicial, “a pesquisa em arquivística na pósgraduação no Brasil”, metamorfoseavase, retomando, de qualquer forma, alguns aspectos não abordados na pesquisa anterior. Como explicitado no relatório final do PIBIC: "Este projeto pretendeu dar continuidade a uma pesquisa que já vinha sendo desenvolvida e cujos resultados parciais já foram publicados" (ALVES, 2003). Nesse plano de trabalho (ALVES, 2003), constavam as seguintes etapas:

\footnotetext{
${ }^{16}$ Os resultados desse projeto de IC, sem incluir as agências financiadoras, seriam apresentados tanto no Congresso de IC da UnB, como no V Enancib, ocorrido em Belo Horizonte, em 2003.
}

1. Revisão de literatura, quando se procedeu às leituras dos textos relacionados ao tema da pesquisa.

2. Mapeamento dos cursos de Arquivologia no Brasil, a fim de se observar a institucionalização desta área.

3. Identificação da participação de professores e alunos dos Cursos de Arquivologia no PIBIC, com o objetivo de obter as seguintes informações a respeito dos projetos de PIBIC: título; nome do orientador; nome do bolsista; data de início e término do projeto (caso já tivesse sido concluído).

4. Continuação do levantamento dos Programas de Pós-graduação no Brasil mais próximos da Arquivística (Ciência da Informação, Comunicação, Biblioteconomia, História), identificando: a universidade; o departamento; as áreas de concentração e as linhas de pesquisa.

5. Levantamento das dissertações e teses de doutorado defendidas nesses programas, cuja temática aproxima-se, pelo objeto e pela abordagem, da Arquivística, identificando-se: os respectivos orientadores; os autores; os departamentos.

6. Levantamento dos projetos de professores dos cursos de pós-gra- 
duação, identificados na etapa d, com temática voltada para a Arquivologia, por meio da pesquisa nos documentos oficiais das agências financiadoras. Devido às dificuldades encontradas, esta etapa não alcançou êxito.

Nas conclusões apresentadas no relatório final do PIBIC (ALVES, 2003), destacavam-se:

- $\quad$ Sobre os projetos PIBIC não se obteve as informações da maioria das universidades que têm graduação em Arquivologia.

- Os projetos com temas aparentemente voltados para a Arquivologia, mas que são vinculados a outros cursos, foram identificados apenas pelos seus títulos, permanecendo a incerteza quanto a real relação temática com esta área. Quanto às teses e dissertações, também com temas relacionados, foi feita uma aproximação pelos títulos dos trabalhos, pois não os lemos, nem tivemos acesso aos resumos destes, quando os identificamos pelos sítios do IBICT ou dos próprios programas de pós-graduação.

- Quanto aos trabalhos de professores da área, que deveriam ser identificados nos arquivos das agências financiadoras, não foi possível, até o momento, a realização desta etapa, permanecendo em aberto.

- A criação dos cursos de graduação em Arquivologia parece ter sensibilizado os cursos de pós-graduação no sentido de acolher temas relacionados à área. Pode-se também levantar como hipótese, por outro lado, que as diferentes formações dos professores dos quadros dos programas de pós podem influenciar a temática, a metodologia, o referencial teórico etc., das pesquisas desenvolvidas. Sabe-se, também, que os cursos de Arquivologia já têm em seus quadros professores com mestrado em Ciência da Informação, cujas dissertações têm como tema a Arquivologia, como é o caso da Universidade de Brasília e da Universidade Federal Fluminense. Este corpo docente dos cursos de Arquivologia, inseridos em departamentos que têm pós-graduação, certamente contribuirão para ampliar a produção científica voltada para a área., criando linhas de pesquisa ou orientando projetos de iniciação científica.

- Quanto ao perfil dos pesquisadores, sejam graduandos ou pósgraduandos, podemos supor que eles provenham de diferentes áreas ou, muitas vezes, estejam vinculados a diferentes departamentos. Por outro lado, 
essa questão mostra a distribuição desigual dos cursos de graduação em Arquivologia e pós-graduação dentro das universidades, ratificada pelo fato de o objeto informação assumir um caráter polissêmico (...). Assim, a questão colocada por Rodrigues e Aparício (2002, p. 38) se essa dispersão é indicadora do caráter inter $\mathrm{e}$ multidisciplinar da Arquivística ou se reflete a ausência (ainda) de uma definição epistemológica da disciplina.

- Os resultados desta pesquisa parecem, portanto, confirmar a hipótese de que o objeto de estudo da Arquivística - a informação orgânica registrada encontra-se disperso em várias áreas do conhecimento, apesar de seu locus institucional estar definido nas ciências sociais aplicadas.

- $\quad$ A revisão bibliográfica permitiunos identificar consideráveis estudos acerca da Ciência da Informação, enquanto em relação à Arquivologia, identificamos apenas dois autores. Como subárea insipiente, de uma área ainda em formação, a Arquivologia carece de produção científica, embora saibamos que os esforços são muitos, não apenas nos departamentos de Ciência da Informação, como também em outros cursos e departamentos, em buscar na institucionalização dos programas de graduação e pós-graduação a cientificidade da área. As instituições arquivísticas também têm-se destacado na realização de pesquisas relacionadas à Arquivologia, fato evidenciado nos projetos financiados pelas agências estaduais de financiamento.

Um forte indicador da importância de um tema de pesquisa é quando ele se desdobra em muitas outras questões e novos problemas são postos. $\mathrm{Ou}$ mesmo quando se muda a perspectiva inicial do tema, inverte-se a pergunta do início, adicionam-se novas variáveis, etc. Esse objeto inicial tem todas essas características. Em 2007, Angelica, agora minha orientanda no mestrado, defenderia sua dissertação de mestrado com o seguinte tema: "Os espaços e os diálogos da formação da arquivística como disciplina no Brasil". A sua dissertação expõe com clareza o seu objeto de pesquisa: "o estudo da formação da Arquivística como disciplina no Brasil". As questões norteadoras da pesquisa indicam o seu programa de trabalho: a) Qual é a trajetória dessa formação? b) Como a Arquivística se configura no campo científico? c) Quais são as suas relações com as outras disciplinas nesse 
processo? A pesquisa incorporava, portanto, parte do que havia sido desenvolvido e publicado em Cenário Arquivístico, no relatório do PIBIC, mas, como era de se esperar, ampliando e aprofundando a temática. Desde o ingresso no mestrado, passando pelo desenvolvimento da pesquisa e sua conclusão, esse objeto de pesquisa foi apresentado em várias edições do Encontro Nacional de Pesquisa e PósGraduação - Enancib, o principal evento científico da área de Ciência da Informação, da qual, não nos esqueçamos, a Arquivologia faz parte como uma subárea, bem como no importante evento internacional Encontro da Associación de Educadores e Investigadores de Bibliotecología, Archivología, Ciencias de la Información y Documentación de Iberoamérica y Caribe - EDIBCIC. Da mesma forma, o tema também foi divulgado nos encontros próprios da Arquivologia, como os Congressos Brasileiros de Arquivologia - CBA, os Congressos Nacionais de Arquivologia CNA e os Congressos de Arquivologia do Mercosul - CAM. Assim, podemos refazer o percurso do tema, seguindo seus rastros nos congressos do Enancib entre 2003 e 2007, produtos de parceria orientanda-orientadora quando da pesquisa de mestrado:

A pesquisa em Arquivística nas universidades brasileiras: um estudo da produção científica no âmbito dos programas de pós-graduação e de iniciação científica. (V Enancib, Belo Horizonte, 2003).

- Questões sobre o lócus acadêmico-institucional da Arquivologia na Ciência da Informação (VI Enancib, Florianópolis, 2005).

- $\mathrm{A}$ iniciação à pesquisa em Arquivística: mapeamento e análise dos projetos de Iniciação Científica dos Cursos de Arquivologia e Biblioteconomia no Brasil (VI CAM, Campos do Jordão, 2005).

- Arquivistas e Arquivologia: lugares de formação, competências e exigências profissionais. (VI CAM, Campos do Jordão, 2005). ${ }^{17}$

- Fronteiras institucionais e de identidade entre a arquivística e a ciência da informação (VII Enancib, João Pessoa, 2006).

\footnotetext{
${ }^{17}$ Com a participação de Larissa Candida Costa, também minha orientanda de mestrado à época. Nesse trabalho realizei o que penso ser um dos sonhos de qualquer orientador: fazer convergir os temas de pesquisa de seus orientandos - ou ao menos de alguns - cujos dados empíricos e bibliografia esclarecem, simultaneamente, dois ou mais problemas de pesquisa.
} 
- A formação dos docentes dos cursos de graduação em Arquivologia no Brasil e seu impacto na produção científica com temáticas arquivísticas e no diálogo interdisciplinar (VII EDIBCIC - Marília/SP, 2006).

- Movimentos da Arquivística no processo de sua consolidação como disciplina: algumas considerações sobre interdisciplinaridade (II CNA, Porto Alegre, 2006).

- A Arquivística no Brasil: emergência de uma profissão, nascimento de uma disciplina (XIV CBA, Rio de Janeiro, 2006).

- A constituição do campo científico da arquivística e suas relações com a ciência da informação (VIII Enancib, Salvador, 2007).

- A trajetória da arquivística no Brasil: marcos temporais e debates iniciais (VII CAM, Viña del Mar, 2007).

Como podemos constatar, a listagem acima mostra que a temática compreende, essencialmente, de fato, a institucionalização da Arquivologia no Brasil. Todos os aspectos abordados nas diferentes comunicações, em diversos congressos, apontam para isso, enfocando os diversos aspectos intrínsecos a esse percurso disciplinar. Entretanto, isso ainda não estava totalmente claro para as pesquisadoras. Revendo esboços do pré-projeto de doutorado de Angelica, com minhas observações, constato que, à época, o nosso tema era o seguinte: "Revisitando os espaços e os diálogos entre a arquivística e a ciência da informação: uma proposta de harmonização do ensino das duas disciplinas no Brasil". O aspecto pragmático do projeto é evidente, uma aposta na convergência disciplinar Arquivologia - Ciência da Informação, daí o foco em um currículo "harmonizado". As questões de pesquisa eram postas assim no pré-projeto de pesquisa de doutorado, amplamente discutido entre ambas, orientanda e orientadora:

a. Se a Arquivística, na sua formação, tem uma relação tradicional com a História, por que suas relações com a Ciência da Informação fortaleceram-se tanto?

b. O fortalecimento dessas relações teria sido decorrente de uma adesão conveniente da Arquivística à Ciência da Informação, tendo-se em vista um reconhecimento social ou teria sido um mero "consenso apático", como pontuam 
Couture, Martineau e Ducharme (1999, P. 33)?

c. Considerando a intensa proximidade entre a Arquivística e a Ciência da Informação, seria viável uma harmonização do ensino entre as duas disciplinas?

d. Essa harmonização se daria na graduação e/ou na pós-graduação?

Embora o cerne do problema a ser pesquisado permeasse todo o projeto, ele parecia ainda não estar claro para nenhuma das duas. Foram necessários muitos encontros, a participação efetiva da coorientadora, a professora Fernanda Sobral do departamento de Sociologia da $\mathrm{UnB}^{18}$ e a tenacidade e disciplina intelectuais de Angelica, para que, pouco a pouco, entendêssemos qual era o problema de pesquisa. Isso se traduzia, por exemplo, na escolha do título da tese de doutorado. Pesquisando nos meus arquivos, constato que tínhamos opção de seis títulos. E o título é a síntese da tese. Contudo, logo ficou claro que era

\footnotetext{
${ }^{18}$ Especialista em sociologia da ciência. Sou infinitamente grata a ela pela coorientação de Angelica. Com certeza o diálogo e a interlocução estabelecidos foram fundamentais para o rumo que a tese tomou.
}

imperativo estudar a fundo a questão da inter/trans/multidisciplinaridade e suas repercussões na Arquivologia. Como agora se tratava de uma tese de doutorado, o orientando bem preparado, começa a superar seu orientador. Não seria diferente com Angelica que, a essa altura, já adquirira a habilidade da escrita científica e o domínio do tema, outro aspecto interessante da formação acadêmico-científica. Para ilustrar, recorro novamente a Booth, Colomb e Williams (2000) quando eles se referem aos "problemas comuns" dos autores de pesquisa científica:

[...] domine o assunto que escolheu, escrevendo sobre ele ao longo de sua pesquisa. [...] Quanto mais escrever, à medida que avança, não importa quão esquematicamente o faça mais confiante estará ao enfrentar o intimidante primeiro rascunho (BOOTH, COLOMB E WILLIAMS, 2000, p. 30, grifos dos autores).

Como apontado anteriormente, Angelica já vinha escrevendo sobre o assunto há tempos o que a conduzia a cada vez mais refletir a respeito, a pesquisar novos autores, novas obras. Até, finalmente, empreender o projeto como ele se delineava, com base nas suas pesquisas empíricas e vasta leitura bibliográfica. Embora o problema não tenha sido posto desta maneira, acho, hoje, que era assim que se apresentava: 
em que medida as interlocuções entre a Arquivologia nacional e a internacional influíram no delineamento da disciplina no Brasil? Nas palavras de Angelica:

O objetivo geral [da tese] é demonstrar como as interlocuções entre as práticas/tendências teóricas arquivísticas internacionais e as nacionais perpassam a institucionalização acadêmica da Arquivologia e o consequente delineamento da área como disciplina científica no Brasil (MARQUES, 2011, p. 35, grifos da autora).

"O estudo deve fornecer elementos para a verificação e a contestação das hipóteses apresentadas", afirma Umberto Eco (1988), referindo-se à cientificidade das pesquisas. A tese de doutorado de Marques (2011) intitulada Interlocuções entre a Arquivologia nacional $e$ a internacional no delineamento da disciplina no Brasil iria aprofundar certos aspectos já estudados na IC e no mestrado. Porém, mais que isso, trouxe novos dados, novas abordagens teórico-metodológica e abriu, creio, novas frentes de pesquisa, ainda que em torno da disciplina. Apontou elementos para que outros a seguissem, aprofundando, expandindo o tema ou, se fosse o caso, contestassem hipótese, dados e tese. Ainda durante o desenvolvimento da pesquisa, os resultados e reflexões parciais iam sendo comunicados nos fóruns científicos, sendo:

- A produção científica relacionada à Arquivística no Brasil: configuração de um campo extradisciplinar (III CNA, Rio de Janeiro, 2008). Ainda em coautoria com a orientadora.

- Os cursos de Arquivologia no Brasil: conquista de espaço acadêmicoinstitucional. (XV CBA, Goiânia, 2008). Ainda em coautoria com a orientadora.

- Os diálogos e as contribuições da Arquivologia no campo da Ciência da Informação (XV CBA - Mesa redonda "Patrimônio cultural arquivístico: Arquivologia, Museologia, Goiânia, 2008).

- A produção científica relacionada à Arquivística no Brasil: configuração de um campo extradisciplinar (III CNA, Rio de Janeiro, 2008). Ainda em coautoria com a orientadora.

- $\quad \mathrm{O}$ intercâmbio internacional na configuração atual do perfil profissional do arquivista brasileiro (XVI CNA, Santos, 2010). Ainda em coautoria com a orientadora.

- Interlocuções entre a Arquivologia internacional e a nacional: referenciais teóricos para a sua compreensão (XI Enancib, Rio de 
Janeiro, 2010). Ainda em coautoria com a orientadora.

- Pesquisas com temáticas arquivísticas na pós-graduação das universidades que abrigam Cursos de Arquivologia: mapeamento das tendências internacionais (IV CNA, Vitória, 2010).

- $\quad$ O campo da informação (XII Enancib, Brasília, 2011).

\section{À guisa de conclusão: o conhecimento}

\section{é cumulativo, se inventa e reinventa}

A tese de doutorado "Interlocuções entre a Arquivologia nacional e a internacional no delineamento da disciplina no Brasill”, representa uma das maiores contribuições à compreensão da Arquivologia no Brasil. O início de tudo encontra-se no desafio de um orientando à sua orientadora, proposto e aceito; na colaboração entre orientadora e orientanda, culminando em um artigo. Um plano de trabalho de iniciação científica proposto a uma estudante prosseguiu no mestrado e desembocou, com novos problemas, no doutorado. Ouso dizer que entre 2001 e 2011 a universidade de Brasília contribuiu sensivelmente para o entendimento da trajetória da Arquivologia no Brasil, traçando um percurso quase inédito no campo da disciplina. Isso não é nem um pouco banal. Por outro lado, a persistência do tema em outros trabalhos, em outras universidades - focado na Arquivologia como disciplina - demonstrou um anseio de pesquisadores da área quanto a conhecer melhor essa disciplina. Muitos outros autores têm-se debruçado sobre o problema, prescrutando-o sob diferentes ângulos. ${ }^{19}$ Nesse sentido, a temática, no caso brasileiro, vai ao encontro de um dos temas identificados no estudo de Couture (2001-2002), quando aquele autor enumera os temas de pesquisa. Couture destaca que na sua investigação sobre temas de pesquisa em Arquivologia, alguns pesquisadores declararam, com relação ao objeto de pesquisa "Arquivologia como disciplina", que suas preferências recaíam sobre estudos:

[...] voltados para o exterior, para discernir melhor o lugar da Arquivologia no universo do conhecimento: interfaces entre a Arquivologia e as outras disciplinas; o lugar da Arquivologia no saber humano; relações com outras ciências da informação (COUTURE, 2001-2002, p. 39, tradução nossa).

19 Particularmente, Silva (2009); Santos (2010); Gomes (2011) para ficarmos em trabalhos produzidos em programas de pós-graduação. 
Para finalizar, gostaria de ressaltar que um dos meus objetivos ao escrever este artigo, em tom quase coloquial e memorialístico, é o de propor uma reflexão sobre a produção de conhecimento em Arquivologia. O tema de pesquisa que escolhi para conduzir o fio da minha narrativa foi proposital. Ele ilustra muito bem um jeito de fazer pesquisa, desde a definição de um tema, seu desenvolvimento e as parcerias que se estabelecem nesse percurso; mostra como os temas podem ser ampliados, revisitados ou reafirmados. Sobretudo, sinaliza para o que poderíamos chamar de "conhecimento progressivo" - ou incremento do conhecimento, como quer Popper (2010) - acerca de um determinado objeto: cada um de nós produz partes de conhecimento, que podem ser quase infinitos, dependendo do problema que nos propomos e do ângulo escolhido. Conhecimento quase caleidoscópico, para o qual concorrem muitos atores, em um diálogo profícuo, ainda que muitas vezes num terreno de conflitos. Retomando a primeira epígrafe que abre este artigo que diz da necessidade de termos consciência de que "todo objeto propriamente científico é consciente e metodicamente construído", eu complementaria dizendo que mesmo inconsciente um problema de pesquisa se insinua na mente do pesquisador e que este, instintivamente, se incomoda e, para livrar-se do incômodo, quase angústia, pesquisa.

\section{Referências}

BOURDIEU, Pierre; CHAMBOREDON, Jean-Claude; PASSERON, Jean-Claude. A profissão de sociólogo. Preliminares epistemológicas. Tradução de Guilherme João de F. Teixeira. Petrópolis : Editora Vozes, 2002.

BOOTH, W. C.; COLOMB, G. G.;WILliAMS, J. M. A arte da pesquisa. Tradução de Henrique A. Rego Monteiro. São Paulo: Martins Fontes, 2000.

CERTEAU, Michel. A escrita da história. Tradução de Maria de Lourdes Menezes. Rio de Janeiro: Forense Universitária, 1982.

COUTURE, Carol. La formation et la recherche en archivistique. Éléments révélateurs de l'état de développement de l'archivistique contemporaine. Synthèse d'un projet de recherche. Archives, Québec, v. 33, n. 2, p. 21-51, 2001-2002. Disponivel em: http://www.archivistes.qc.ca/revuearchiv es/vol33_2/33-2-couture.pdf

COUTURE, Carol. ; MARTINEAU, Jocelyne; DUCHARME, Daniel. A formação e a pesquisa em arquivística no mundo contemporâneo. Tradução Luís Carlos Lopes. Brasília: FINATEC, 1999.

DUBY, Georges. A história continua. Tradução Clóvis Marques. Rio de 
Janeiro: Jorge Zahar Editor/Editora UFRJ, 1993.

ECO, Umberto. Como se faz uma tese. Tradução Gilson Cesar Cardoso de Souz. São Paulo: Perspectiva, 1988.

FONSECA, Maria Odila Khal. Arquivologia e Ciência da Informação: (re)definição de marcos interdisciplinares. 2004. 181 f. Tese (Doutorado em Ciência da Informação) Universidade Federal do Rio de Janeiro, Rio de Janeiro, 2004.

GOMES, Yuri. Processos de institucionalização do campo arquivístico no Brasil (1971-1978): entre a memória e a história. $151 \mathrm{f}$. Dissertação (Mestrado em Memória Social) - Universidade Federal do Estado do Rio d Janeiro, Rio de Janeiro, 2011.

JAHANBEGLOO, Ramin. George Steiner: à luz de si mesmo. Tradução de Fany Kon e J. Guinsburg. São Paulo: Editora Perspectiva, 2003.

JARDIM, José Maria; FONSECA, Maria Odila Kahl (Org,) A formação do arquivista no Brasil. Niterói: EdUFF, 1999.

MARQUES, Angelica Alves da Cunha. Os espaços e os diálogos da formação e configuração da Arquivística como disciplina no Brasil. 2007. 298 f. Dissertação (Mestrado em Ciência da Informação) - Universidade de Brasília, Brasília, 2007.

MARQUES, Angelica Alves da Cunha . O campo da informação. In: XII Encontro Nacional de Pesquisa em Ciência da Informação, 2011, Brasília. XII ENANCIB: políticas de informação para a sociedade. Brasília: Thesaurus, 2011.

MARQUES, Angelica Alves da Cunha . Interlocuções entre a arquivologia nacional $e$ a internacional no delineamento da disciplina no Brasil. 399 fl. (Tese de Doutorado) - Faculdade de Ciência da Informação, Universidade de Brasília, Brasília, 2011.

MARQUES, Angelica Alves da Cunha; RODRIGUES, Georgete Medleg. O intercâmbio internacional na configuração atual do perfil profissional do arquivista brasileiro. In: Congresso Nacional de Arquivologia, 2010, Santos. XVI Congresso Nacional de Arquivologia, 2010.

MARQUES, Angelica Alves da Cunha . Pesquisas com temáticas arquivísticas na pós-graduação das universidades que abrigam Cursos de Arquivologia: mapeamento das tendências internacionais. In: Congresso Nacional de Arquivologia, 2010, Vitória. IV Congresso Nacional de Arquivologia, 2010.

MARQUES, Angelica Alves da Cunha ; RODRIGUES, Georgete Medleg . Interlocuções entre a Arquivologia internacional e a nacional: referenciais teóricos para a sua compreensão. In: XI ENANCIB, Rio de Janeiro, 2010.

MARQUES, Angelica Alves da Cunha ; RODRIGUES, Georgete Medleg . A Arquivística nos Encontros Nacionais de Pesquisa em Ciência da Informação (ENANCIB's): análise preliminar da influência do pensamento arquivistico internacional. In: $\mathbf{X}$ Encontro Nacional de Pesquisa em Ciência da Informação, 2009, João Pessoa. A responsabilidade social da Ciência da Informação, 2009. 
MARQUES, Angelica Alves da Cunha ; RODRIGUES, Georgete Medleg . A Arquivística e seus diálogos: relações que se tecem no seu percurso extradisciplinar. In: CINFORM, 2008, Salvador. VIII CINFORM, 2008.

MARQUES, Angelica Alves da Cunha ; RODRIGUES, Georgete Medleg . Os cursos de Arquivologia no Brasil: conquista de espaço acadêmicoinstitucional. In: XV Congresso Brasileiro de Arquivologia, 2008, Goiânia. XV CBA, 2008.

MARQUES, Angelica Alves da Cunha . Os diálogos e as contribuições da Arquivologia no campo da Ciência da Informação. In: XV Congresso Brasileiro de Arquivologia - Mesa redonda "Patrimônio cultural arquivístico: Arquivologia, Museologia, Biblioteconomia", 2008, Goiânia. XV CBA, 2008.

MARQUES, Angelica Alves da Cunha ; RODRIGUES, Georgete Medleg . A produção científica relacionada à Arquivística no Brasil: configuração de um campo extradisciplinar. In: III Congresso Nacional de Arquivologia, 2008, Rio de Janeiro. Anais do III Congresso Nacional de Arquivologia, 2008.

MARQUES, Angelica Alves da Cunha ; RODRIGUES, Georgete Medleg . A trajetória da Arquivística no Brasil: marcos temporais, debates iniciais. In: VII Congresso de Arquivologia do Mercosul, 2007, Viña del Mar. Anais do VII CAM, 2007.

MARQUES, Angelica Alves da Cunha ; RODRIGUES, Georgete Medleg . A constituição do campo científico da arquivística e suas relações com a
Ciência da Informação. In: VIII Encontro Nacional de Pesquisa em Ciência da Informação, 2007, Salvador. Anais do VIII ENANCIB, 2007.

MARQUES, Angelica Alves da Cunha ; RODRIGUES, Georgete Medleg ; COSTA, Larissa Cândida . Arquivistas e Arquivologia: lugares de formação, competências e exigências profissionais. In: VI Congresso de Arquivologia do Mercosul, 2005, Campos do Jordão - SP. Anais do VI Congresso de Arquivologia do Mercosul, 2005.

MARQUES, Angelica Alves da Cunha ; RODRIGUES, Georgete Medleg . A iniciação à pesquisa em Arquivística: mapeamento e análise dos projetos de Iniciação Científica dos Cursos de Arquivologia e Biblioteconomia no Brasil.. In: VI Congresso de Arquivologia do Mercosul, 2005, Campos do Jordão - SP. Anais do VI Congresso de Arquivologia do Mercosul, 2005.

MARQUES, Angelica Alves da Cunha ; RODRIGUES, Georgete Medleg . A Pesquisa em Arquivística nas Universidades Brasileiras: um estudo da produção científica no âmbito dos programas de pós-graduação e de iniciação científica. In: V Encontro Nacional de Pesquisa em Ciência da Informação, Belo Horizonte: UFMG, 2003.

MILLER, David (Org.) Karl Popper. Textos escolhidos. Tradução Vera Ribeiro. Rio de Janeiro: Contraponto, 2010.

RODRIGUES, Georgete Medleg ; MARQUES, Angelica Alves da Cunha . Movimentos da Arquivística no processo de sua consolidação como disciplina: algumas considerações sobre 
interdisciplinaridade. In: II Congresso Nacional de Arquivologia, 2006, Porto Alegre. Anais do II Congresso Nacional de Arquivologia.

RODRIGUES, Georgete Medleg ; MARQUES, Angelica Alves da Cunha . A Arquivística no Brasil: emergência de uma profissão, nascimento de uma disciplina. In: XIV Congresso Brasileiro de Arquivologia, 2006, Rio de Janeiro. Anais do XIV Congresso Brasileiro de Arquivologia.

RODRIGUES, Georgete Medleg ; MARQUES, Angelica Alves da Cunha . A formação dos docentes dos cursos de graduação em Arquivologia no Brasil e seu impacto na produção científica com temáticas arquivísticas e no diálogo interdisciplinar. In: VII Encuentro de Educadores e Investigadores en Bibliotecología, Archivologia, Ciencias de la Información y de la Documentación de Iberoamérica y el Caribe (EDIBCIC), 2006, Marília. VII EDIBICIC. Marília, 2006.

RODRIGUES, Georgete Medleg ; MARQUES, Angelica Alves da Cunha . Fronteiras institucionais e de identidade entre a Arquivística e a Ciência da Informação. In: VII Encontro Nacional de Pesquisa em Ciência da Informação (ENANCIB), 2006, Marília. VII ENANCIB. Marília, 2006.

RODRIGUES, Georgete Medleg ; MARQUES, Angelica Alves da Cunha . Questões sobre o Locus AcadêmicoInstitucional da Arquivologia na Ciência da Informação. In: VI Encontro Nacional de Pesquisa em Ciência da Informação, 2005, Florianopólis - SC. Anais do VI ENANCIB, 2005.

RODRIGUES, Georgete Medleg; APARICIO, Maria Alexandra Miranda.
A pesquisa em Arquivística na pósgraduação no Brasil: balanço e perspectivas. Cenário Arquivístico, Brasília, DF, v. 1, n. 1, jan./jun. 2002, p. 31-39.

SANTOS, Paulo Elian dos. Arquivística no laboratório: história, teoria e métodos de uma disciplina. Rio de Janeiro: Teatral, Faperj, 2010.

SILVA, Eliezer Pires da. A noção de informação arquivística na produção de conhecimento em Arquivologia no Brasil (1996-2006). 135 f. Dissertação (Mestrado em Ciência da Informação) Universidade Federal Fluminense, Niterói, 2009. 